\title{
Disaster Preparedness Should Represent an Augmentation of the Everyday Trauma System - But Are We Prepared?
}

Jørgen Joakim Jørgensen ( $\sim$ Joakim.jorgensen@traumatologi.no )

Oslo University Hospital https://orcid.org/0000-0003-0876-1296

Peter Wiel Monrad-Hansen

Oslo University Hospital

Christine Gaarder

Oslo University Hospital \& Faculty of Medicine, University of Oslo

Pål Aksel Næss

Oslo University Hospital \& Faculty of Medicine, University of Oslo

Original research

Keywords: Preparedness, MCl, Competency

Posted Date: October 2nd, 2020

DOI: https://doi.org/10.21203/rs.3.rs-84135/v1

License: (a) (i) This work is licensed under a Creative Commons Attribution 4.0 International License. Read Full License 


\section{Abstract}

\section{Introduction}

Mass casualty incidents $(\mathrm{MCl})$ range from natural disasters to terrorist attacks. The increased frequency, geographical spread and the heterogenicity in type of terror incidents, challenge healthcare systems all over the world. Trauma systems constitute the base upon which disaster preparedness is being build. The largest $\mathrm{MCl}$ in Norway took place 22 July 2011 and several lessons were learnt including the importance of having designed the everyday trauma infrastructure to be able to increase activity and adjust according to needs. Norway is sparsely populated, with a national trauma system consisting of four regional trauma centers (TCs) and 35 acute care hospitals treating trauma (non-trauma centers; NTCs) We wanted to assess how well hospitals fill the national trauma system requirements for competence, and the degree of awareness of existing $\mathrm{MCl}$ plans.

\section{Methods}

We conducted a cross-sectional survey of the on-call trauma team in all 39 Norwegian hospitals during two time periods: July-August (HS; holiday season) and September - June (NHS; non-holiday season). A standardized questionnaire was used to evaluate the $\mathrm{MCl}$ preparedness.

\section{Results}

A total of 347 trauma team members participated with 173 during HS and 174 during NHS. Over $95 \%$ of the team members were aware of the hospital $\mathrm{MCl}$ plan, only half had read the plan during the last 6 months, whereas $63 \%$ at the TCs and $74 \%$ at NTCs were confident with their designated role in the event of an $\mathrm{MCl}$. Trauma team exercises were conducted regularly and $86 \%$ had ever participated, primarily residents and nurses. Only $63 \%$ at the TCs and $53 \%$ at the NTCs had participated in an $\mathrm{MCl}$ exercise. The proportion of resident surgeons and anesthetists with $>4$ years clinical experience was significantly higher in TCs (88\% and 63\%) than in NTCs (27\% and $17 \%)$. At NTCs $38 \%$ of the resident surgeons were on call from home after working hours. All the on-call consultant surgeons were at home after working hours, leaving interns in charge at several of the hospitals. All resident surgeons at the TCs were ATLS providers compared to $64 \%$ at the NTCs and almost $90 \%$ of the consultant surgeons had participated in advanced trauma surgical courses.

\section{Conclusion}

Despite increased focus on disaster preparedness at a national level after the 2011 attacks, we identified limited compliance with trauma system requirements concerning competency and training. Strict guidelines to secure immediate notification and early presence of consultants whenever a situation that might turn into an $\mathrm{MCl}$ occurs should be a prerequisite. The awareness and content of existing $\mathrm{MCl}$ plans should be continuously improved to be able to meet the challenges of future $\mathrm{MCls}$. 


\section{Background}

Mass casualty incidents (MCls) are occurring frequently worldwide ranging from terrorist attacks to natural disasters. On that background, healthcare systems need to be prepared for the next possible event. Four aspects of trauma care have been identified being valuable for $\mathrm{MCI}$ preparedness and response: communication, triage, transport and training.(1)

Accurate prehospital triage is essential to ensure optimal patient flow, in order to avoid that the closest facilities get a disproportionally high number of patients.(2) Hospitals play a critical role in the system. The hospital $\mathrm{MCl}$ definition will vary with available local resources and capacity as well as trauma patient volumes meanwhile the outcome to a large extent will depend on trauma experience and competence.(3) Hospital $\mathrm{MCl}$ plans have been developed in an effort to prepare the hospitals for situations when their surge capacity becomes challenged.(4) In order to be functional, a well-designed $\mathrm{MCl}$ plan should be based on the everyday trauma organization, adjusted for the specific needs of multiple patients.

In addition to implementing and maintaining a trauma system, $\mathrm{MCl}$ plans should mandate regular training and testing of the different elements of the plan including tabletop exercises for core personnel. (5) The individual task of the hospital staff on the other hand is to fill the competency requirements and to know their own role in an $\mathrm{MCl}$.

In Norway, the initial national trauma plan was designed in 2007, a first version was implemented in the South East health region in 2010. The plan describes 2 levels of care: regional trauma center (TC) and non-trauma center (NTC). The NTCs have general surgical capabilities $24 / 7$ and should be able to provide initial care, including damage control resuscitation, before transfer of severely injured patients to the regional TC. Based on these concrete recommendations and the lessons learned after the largest terrorist attack in Norway on July 22, 2011,(6-9) the national trauma plan was revised in 2017. The plan describes all aspects of trauma care including individual competencies, course requirements and team training.(10)

In this study we wanted to investigate the individual awareness of the $\mathrm{MCl}$ plan and adherence to defined trauma team requirements in all hospitals receiving trauma patients in Norway through a telephone interview of the on-call trauma team key personnel at 2 different time points.

\section{Materials And Methods}

Norway has 5.3 million inhabitants and is organized in four health care regions (population range 400.000 to 3.2 million), each with a regional TC similar to a US level-I or level-II trauma center.(11) Each region has 4-14 NTCs admitting trauma patients. These hospitals will have general surgical capabilities 24/7, and the ability to stabilize and transfer patients to the TC according to predefined transfer criteria. Hospital patient population vary greatly(12) and the hospitals will have different thresholds for $\mathrm{MCls}$ ranging from 2-12 critically injured patients. The only equivalent to a level 1 trauma center (11) in 
Norway is Oslo University Hospital (OUH-U) in the southeastern health region covering 3,2 million inhabitants.

We conducted a cross-sectional survey during the period August 2017 to June 2018 at all 39 hospitals admitting trauma patients in Norway, focusing on relevant trauma system requirements and degree of $\mathrm{MCl}$ plan awareness. Personnel in the four TCs and 35 NTCs were interviewed in July/August (holiday season; HS) and September-June (non-holiday season; NHS). The telephone interview consisted of standardized questions presented to the on-call emergency room (ER) nurse, senior resident surgeon, senior resident anesthetist, consultant surgeon and consultant anesthetist (Table 1). These health care workers would be essential in the early stage of an $\mathrm{MCl}$. The interviews were based on voluntary participation and were conducted by two consultant trauma surgeons at OUH on weekdays between 8 am and $4 \mathrm{pm}$. 
Table 1

Translated version of the topics in the survey

Years of experience

ATLS / Trauma nursing course*

DSTC**

Knowledge of the hospital's MCI plan

Read $\mathrm{MCl}$ plan within last 6 months

Familiar with own role during an $\mathrm{MCl}$

Would feel competent during an $\mathrm{MCl}$

Confident with own hospital's competency during an $\mathrm{MCl}$

Increased focus on MCI preparedness after July 22, 2011

Number of trauma team simulations per year

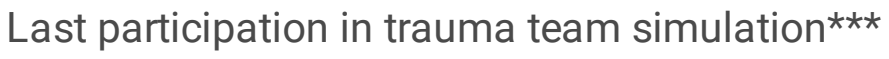

Hospital $\mathrm{MCl}$ exercises per year

Last participation in $\mathrm{MCl}$ alertness exercise ${ }^{\star \star \star}$

Hospital triage tabletop exercises per year

Last participation in triage tabletop exercise***

Hospital ER evacuation exercises per year

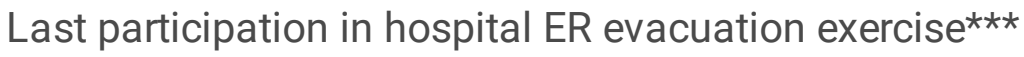

Hospital ICU evacuation exercises per year

Last participation in hospital ICU exercise ${ }^{\star \star \star}$

Hospital MCl exercises per year

Last participation on hospital $\mathrm{MCl}$ exercise ${ }^{\star \star \star}$

ATLS, advanced trauma life support; *TNCC (trauma nursing care course), ATCN (advanced trauma care for nurses) or KITS (Norwegian trauma care course); DSTC, definitive surgical trauma care; ${ }^{* *}$ or

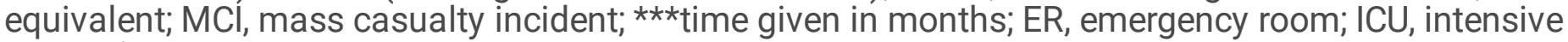
care unit

Statistical analyses comparing the two time periods and TCs compared to NTCs were done with SPSS version 25 (SPSS, Chicago, IL, USA). Kolmogorov-Smirnov/Shapiro Wilk histograms and normal-quartile plots were used to test for normality. Numerical data are reported as median with interquartile range (IQR) 
and categorical data as frequencies ( $n$ ) and percentages (\%). Mann-Whitney U-test was used to compare numerical data and Fisher's test or chi-squared test was used to compare categorical data. Statistical significance was set as a two tailed p-value of $<0.05$.

The institutional Data Protection Officer at OUH had no objections to this study.

\section{Results}

Of the interviewed trauma team members, 347 participated with 173 in HS and 174 in NHS. Two persons opted out leaving 155 consultants, 114 residents and 78 nurses participating in the survey (Table 2). Fourteen NTCs had an attending consultant anesthetist as the only anesthetist on call.

Table 2

Number of personnel in different categories

\begin{tabular}{|llll|}
\hline & & TC & NTC \\
\hline Anesthesia & Consultant, in-house & 5 & 27 \\
\hline & Consultant, standby* & 3 & 43 \\
\hline & Resident, in-house & 8 & 33 \\
\hline Resident, standby* & 0 & 2 \\
\hline Surgery & Consultant, in-house & 0 & 0 \\
\hline & Consultant, standby* & 8 & 69 \\
\hline & Resident, in-house & 8 & 39 \\
\hline Rurse & Resident, standby* & 0 & 24 \\
\hline TC, Trauma center; NTC, Non-trauma center. *30 min standby-time \\
\hline
\end{tabular}

There were no statistical differences between the two time periods.

The number of personnel in the different categories is shown in Table 2. A total of 40 staff was interviewed at TCs and 307 at NTCs. As shown in Table 3 the TCs had more experienced residents compared to NTCs. The proportion of surgical residents with $>4$ years' experience was $88 \%$ in TCs and $27 \%$ in NTCs $(p<0.05)$. For anesthesiology residents, the trend was similar with $63 \%$ in the TCs and $17 \%$ in NTCs $(p<0.05)$. All on-call consultant surgeons $(100 \%)$ and more than half of the consultant anesthetists (38\% at TCs, $61 \%$ at NTC) had to be called in from home after working hours. There was no difference between the experiences of ER nurses at TCs compared to NTCs. 
Table 3

Experience and provider status in different personnel categories

\begin{tabular}{|c|c|c|c|}
\hline & & $\mathrm{TC}$ & NTC \\
\hline \multirow[t]{5}{*}{ Anesthesia } & Consultant experience in years & $20(15-29)$ & $20(12-29)$ \\
\hline & Consultant ATLS provider, n (\%) & $7(88)$ & $57(81)$ \\
\hline & Resident experience in years & $4(3-11)$ & $3(2-3) \star$ \\
\hline & Resident over 4 years' experience, n (\%) & $5(63)$ & $6(17)^{\star}$ \\
\hline & Resident ATLS provider, $\mathrm{n}(\%)$ & $6(75)$ & $19(54)^{\star}$ \\
\hline \multirow[t]{7}{*}{ Surgery } & Consultant experience in years & $16(14-31)$ & $23(14-28)$ \\
\hline & Consultant ATLS provider, n (\%) & $5(63)$ & $60(87)^{\star}$ \\
\hline & Consultant DSTC provider, n (\%) & $7(88)$ & $62(90)$ \\
\hline & Resident experience in years & $6(5-8)$ & $2(1-4)^{*}$ \\
\hline & Resident over 4 years' experience, $n$ (\%) & $7(88)$ & $17(27)^{\star}$ \\
\hline & Resident ATLS provider, $\mathrm{n}(\%)$ & $8(100)$ & $40(64)^{\star}$ \\
\hline & Resident DSTC provider, n (\%) & $8(100)$ & $20(32)^{*}$ \\
\hline \multirow[t]{2}{*}{ Nurse } & Experience in years & $10(5-29)$ & $12(5-20)$ \\
\hline & Trauma nursing course provider, $\mathrm{n}(\%)$ & $6(75)$ & $63(90)$ \\
\hline
\end{tabular}

Advanced Trauma Life Support (ATLS) is a course for doctors focusing on the initial assessment and management meanwhile Definitive Surgical Trauma Care (DSTC) is a course for surgical teams focusing on surgical decision-making. All surgical residents at the TCs were ATLS and DSTC providers compared to $64 \%$ and $32 \%$ at the NTCs, respectively. A higher proportion of resident anesthetists were ATLS providers at the TCs compared to NTCs $(75 \%$ vs $54 \%, p<0,05)$. Almost $90 \%$ of the consultant surgeons were DSTC providers meanwhile significantly fewer consultant surgeons were ATLS providers at the TCs compared to the NTCs $(63 \%$ vs $87 \%, p<0,05)$.

Over $95 \%$ of the study population was aware of the hospital $\mathrm{MCl}$ plan but only half had read the plan during the last 6 months with no difference between the personnel in TCs and the NTCs (Table 4). More than $85 \%$ of all the interviewed persons were familiar with their $\mathrm{MCl}$ role meanwhile fewer felt confident in fulfilling the role (63\% in TCs vs $74 \%$ in NTCs, NS). The majority were confident with their hospital's level 
of competence and more staff at TCs compared to NTCs reported an increased $\mathrm{MCl}$ awareness in their institution after July 22, 2011 (78\% vs 56\%, p < 0.05) (Table 4).

Table 4

Reported MCl preparedness

\begin{tabular}{|lcc|}
\hline & TC & NTC \\
\hline Knowledge of the hospital's MCI plan & $37(93)$ & $294(96)$ \\
\hline Read MCl plan within last 6 months & $19(48)$ & $160(52)$ \\
\hline Familiar with own role during an MCl & $33(83)$ & $271(88)$ \\
\hline Would feel competent during an MCl & $25(63)$ & $226(74)$ \\
\hline Confident with own hospital's competency during an MCl & $34(85)$ & $249(81)$ \\
\hline Increased focus on MCl preparedness after July 22, 2011 & 31 (78) & $171(56)^{*}$ \\
\hline $\begin{array}{l}\text { Values are in n (\%); TC, trauma center; NTC, non-trauma center; } \mathrm{MCl} \text {, mass casualty incident; * denotes } \\
\text { P-value<0,05 }\end{array}$ & \\
\hline
\end{tabular}

Regular simulated training was conducted in all hospitals. The vast majority of personnel $(86 \%, 299 / 347)$ had participated in a trauma team exercise with significantly more in NTCs compared to TCs (89\% vs 68\%) (Table 5). Median time in months since the last trauma team training participation was 3 for staff at NTCs compared to 6 at TCs with the majority performed by residents. 
Table 5

$\mathrm{MCl}$ maintenance

\begin{tabular}{|lll|}
\hline & TC & NTC \\
\hline Participated in TT simulation, $\mathrm{n}(\%)$ & $27(68)$ & $272(89)^{\star}$ \\
\hline Last participation in trauma team simulation & $6(2-36)$ & $3(2-8)^{\star}$ \\
\hline Participated in MCI alertness exercise, $\mathrm{n}(\%)$ & $31(78)$ & $208(68)$ \\
\hline Last participation in MCl alertness exercise & $2(1-6)$ & $2(1-6)$ \\
\hline Participated in triage exercise, $\mathrm{n}(\%)$ & $12(30)$ & $70(23)$ \\
\hline Last participation in triage tabletop exercise & $7(2-24)$ & $11(4-20)$ \\
\hline Participated in hospital ER evacuation exercise, $\mathrm{n}(\%)$ & $7(18)$ & $44(14)$ \\
\hline Last participation in hospital ER evacuation exercise & $18(9-24)$ & $15(7-36)$ \\
\hline Participated in hospital ICU exercise, $\mathrm{n}(\%)$ & $1(3)$ & $31(10)$ \\
\hline Last participation in hospital ICU exercise & $18(18-18)$ & $12(6-24)$ \\
\hline Participated in hospital MCl exercise, $\mathrm{n}(\%)$ & $25(63)$ & $164(53)$ \\
\hline Last participation on hospital MCl exercise & $18(9-30)$ & $12(6-24)$ \\
\hline $\begin{array}{l}\text { Values are months, median IQR (interquartile range) unless stated otherwise; TC, trauma center; NTC, } \\
\text { non-trauma center; MCl, mass casualty incident; TT, trauma team; }{ }^{*} \text { denotes P-value< 0,05 }\end{array}$ \\
\hline
\end{tabular}

$\mathrm{MCl}$ alertness exercises were conducted with a median of every second month for both TCs and NTCs, and the majority reported having participated in such (78\% in TCs and $68 \%$ in NTCs, respectively (NS)). Less than $25 \%$ had participated in a triage exercise and less than $15 \%$ had participated in ER and/or ICU evacuation exercises. Far more had participated in a full-scale hospital $\mathrm{MCl}$ exercise $(63 \%$ at TCs vs $53 \%$ at NTCs, NS) (Table 5).

\section{Discussion}

We performed a national survey assessing awareness and knowledge of $\mathrm{MCl}$ plans and adherence to relevant trauma system criteria. Although more than $95 \%$ of the interviewed trauma team members were aware of their hospital's $\mathrm{MCl}$ plan, limited compliance with trauma system requirements concerning competency and training was identified both in TCs and NTCs.

Recent studies, including the experience gained in Norway on July 22, 2011,(7) have demonstrated that the closest hospital in the event of an $\mathrm{MCl}$ will receive the highest number of patients indicating the need for $\mathrm{MCl}$ preparedness at all hospitals receiving trauma victims.(13-15) 
Most Norwegian hospitals have limited exposure to trauma, i.e. receive very few severely injured on an annual basis, and have limited surgical trauma competency.(12) However, due to the settlement pattern in Norway including a lot of small communities with long transportation distances to the regional TC, the NTCs have to be prepared to take care of severely injured patients under normal circumstances as well as under an $\mathrm{MCl} .(12,16,17)$

Obviously, regular training, both theoretical and practical, becomes even more important in the NTCs if adequate trauma care in daily practice and in an $\mathrm{MCl}$ situation is to be delivered.(18) Only $27 \%$ of the surgical residents in NTCs reported at least 4 years of surgical training which is a minimum to fulfill the role as team leader during a regular trauma team activation according to the criteria in the national trauma plan. On that background, the consultant surgeon on call will have to take on the role as trauma team leader in almost every Norwegian NTC and almost $90 \%$ of the interviewed consultant surgeons working in NTCs reported to be ATLS trained which is another prerequisite to fulfill that role. Moreover, as severely injured patients might need damage control surgery as part of initial care, surgeons need to be specifically trained for this. Advanced surgical course participation (like DSTC) is another criterion to be met and $90 \%$ of consultant surgeons at NTCs were DSTC trained and represents a major improvement compared to the situation before July 22, 2011.(19)

As only $32 \%$ of resident surgeons at NTCs were DSTC trained, the need for early consultant surgeon presence is evident. Even though most consultant surgeons were DSTC providers, their real $\mathrm{MCl}$ and trauma surgery experience is limited. $(6-9,20)$ Frequent, goal directed training is therefore a prerequisite to achieve acceptable preparedness in all Norwegian hospitals. Training for MCls results in improved skills, knowledge and attitudes,(21) and the outcome of an $\mathrm{MCl}$ is largely dependent on preparedness.(3)

Trauma team training is especially important in low volume centers and in our study almost $90 \%$ of the interviewed health care workers at NTCs had participated within the last 3 months. Fewer (68\%) had participated in trauma team training at TCs probably reflecting that the frequency of trauma team training is not proportional to the number of staff. That the physician-based roles in the team training in TCs were mainly covered by residents might be attributed to the fact that they are more experienced compared to the interviewed residents at NTCs. However, senior staff should be present to supervise and interfere both during training and real situations to improve performance and outcomes. $(22,23)$ The interviewed nursing staff reported high levels of experience and competence both in NTCs and TCs. Their important role in the trauma team cannot be overestimated including their roles as continuity carriers.

Our study revealed that in the NTCs no consultant surgeons and less than $40 \%$ of the consultant anesthetists on call are in-house after normal working hours. Hence, simple and written guidelines to secure immediate notification and early presence of the consultants under ordinary trauma team activations as in a possible $\mathrm{MCl}$ situation should be mandatory.

An $\mathrm{MCl}$ plan is the core of a hospital's $\mathrm{MCl}$ preparedness. $(4,5,24)$ Trauma care in the event of an $\mathrm{MCl}$ should be based on a trauma system's everyday practice. $(1,5,20) \mathrm{MCl}$ plans should be readily available and healthcare workers need to be familiar with their role and confident with their function during an $\mathrm{MCl}$. 
In our study over $95 \%$ were aware of the $\mathrm{MCl}$ plan but only $50 \%$ had read the plan within the last 6 months. One can argue that knowledge of the plan is enough. In our study, on the other hand, more than $25 \%$ were not sure whether they could fulfill their designated role during an $\mathrm{MCl}$, possibly reflecting the lack of regular training. Moreover, only $54 \%$ of the interviewed personnel had ever participated in a hospital $\mathrm{MCl}$ exercise, possibly reflecting an ever-increasing demand for hospital effectiveness. However, Norwegian law mandates all hospitals to have an $\mathrm{MCl}$ plan, conduct exercises and train all relevant personnel. $(25,26)$ As full-scale $\mathrm{MCl}$ exercises and evacuating hospital units has an economic cost and might affect outcome in ordinary patients negatively, cheaper alternatives have to be sought. Although small scale exercises, such as tabletop triage training, are valuable options, $(5,27)$ in our study less than $25 \%$ reported such an experience. The need to evacuate the ED is a challenging task but described recently by Hojman and coworkers after the Boston marathon bombing.(28) Although only $14 \%$ had ever participated in an ED evacuation exercise in our study, preparation and training at OUH-U lead to a successful evacuation of the ED in 45 minutes during the twin terrorist attack in 2011.(6)

\section{Limitations}

This cross-sectional study was performed by telephone interviews of the on-call trauma team members. Team members were asked to respond to a predefined set of relevant questions (Table 1). This might lead to communication difficulties including unpredicted unclarities in some of the questions.(19, 29) A pilot test of the questionnaire might have reduced the uncertainty the interviewed personnel experienced. However, sufficient time was set aside for clarification if needed during the interviews.

Competence and experience among the personnel on call will vary in every hospital on a daily basis. The design of the study might lead to bias since it reflects the competence at a given time point. Performing interviews at two different time periods was done to reduce such effects.

Some of the questions were related to the respondents' memory of the last time different categories of exercises were performed. Since some exercises had more relevance to one personnel group than to others, that might influence the responses. The reported frequency of training is likely due to recall bias or simply describes the respondent's own participation in team training. Finally, self-assessment is subjective and introduces a bias per definition.

\section{Conclusion}

Despite increased focus on disaster preparedness at a national level after the 2011 attacks, we identified limited compliance with trauma system requirements concerning competency and training with reference to daily trauma care as well to $\mathrm{MCl}$ situations. Strict guidelines to secure immediate notification and early presence of consultants whenever a situation that might turn into an $\mathrm{MCl}$ occurs should be a prerequisite. The awareness and content of existing $\mathrm{MCl}$ plans should be continuously improved to be able to meet the challenges of future MCls. 


\section{Declarations}

- Ethical approval and consent to participate: The institutional Data Protection Officer at OUH had no objections to this study

- Consent for publication: Not applicable

- Availability of data and material: The datasets during and/or analysed during the current study is available from the corresponding author on reasonable request

- Competing interests: None reported

- Funding: None of the authors have any financial and personal relationships with other people or organizations that could inappropriately influence their work. There are no financial or non-financial competing interests

- Authors' contributions: All authors have made contributions to the design of the study, analysis and interpretation of data, and drafting and revising the manuscript. They have all given final approval of the version to be submitted and have given permission for their names to be included as co-authors

- Acknowledgements: Not applicable

\section{References}

1. Bachman SL, Demeter NE, Lee GG, Pediatric RBC, 2014. The impact of trauma systems on disaster preparedness: a systematic review. Clinical Pediatric Emergency Medicine. 2014 Dec 1;15(4):296308.

2. Melmer P, Carlin M, Castater CA, Koganti D, Hurst SD, Tracy BM, et al. Mass Casualty Shootings and Emergency Preparedness: A Multidisciplinary Approach for an Unpredictable Event. J Multidiscip Healthc. 2019;12:1013-21.

3. Ben-Ishay O, Mitaritonno M, Catena F, Sartelli M, Ansaloni L, Kluger Y. Mass casualty incidents - time to engage. World J Emerg Surg. BioMed Central; 2016;11(1):1-3.

4. Sayed El M, Chami AF, Hitti E. Developing a Hospital Disaster Preparedness Plan for Mass Casualty Incidents: Lessons Learned From the Downtown Beirut Bombing. Disaster Med Public Health Prep. Cambridge University Press; 2017 Sep 20;1:1-7.

5. Hirshberg A, Holcomb JB, Mattox KL. Hospital trauma care in multiple-casualty incidents: A critical view. Annals of Emergency Medicine. 2001 Jun 21;37(6):647-52.

6. Gaarder C, Jørgensen JJ, Kolstadbraaten KM, Isaksen KS, Skattum J, Rimstad R, et al. The twin terrorist attacks in Norway on July 22, 2011: the trauma center response. J Trauma Acute Care Surg. 2012 Jul;73(1):269-75.

7. Waage S, Poole JC, Thorgersen EB. Rural hospital mass casualty response to a terrorist shooting spree. Br J Surg. John Wiley \& Sons, Ltd; 2013 Jul 10;100(9):1198-204.

8. Sollid SJ, Rimstad R, Rehn M, Nakstad AR, Tomlinson A-E, Strand T, et al. Oslo government district bombing and Utøya island shooting July 22, 2011: the immediate prehospital emergency medical 
service response. Scand J Trauma Resusc Emerg Med. 2012 Jan 26;20(1):1-12.

9. Rimstad R, Sollid SJ. A retrospective observational study of medical incident command and decision-making in the 2011 Oslo bombing. Int J Emerg Med. Springer Berlin Heidelberg; 2015;8(1):1-10.

10. NKT-T Working Group. National traumaplan-Traumasystem in Norway 2016 [Internet]. www.traumatologi.no; 2016. 122 p. Available from: www.traumeplan.no

11. American College of Surgeons. Resources for optimal care of the injured patient 2014. Chicago IL, American College of Surgeons Committee on Trauma; 2014.

12. Dehli T, Gaarder T, Christensen BJ, Vinjevoll OP, Wisborg T. Implementation of a trauma system in Norway: a national survey. Acta Anaesthesiol Scand. 2015 Mar;59(3):384-91.

13. Carles M, Levraut J, Gonzalez JF, Valli F, Bornard L. Mass casualty events and health organisation: terrorist attack in Nice. The Lancet. Elsevier; 2016 Nov 12;388(10058):2349-50.

14. de Ceballos JPG, Turegano-Fuentes F, Pérez-Díaz D, Sanz-Sánchez M, Martin-Llorente C, GuerreroSanz JE. 11 March 2004: The terrorist bomb explosions in Madrid, Spain-an analysis of the logistics, injuries sustained and clinical management of casualties treated at the closest hospital. Crit Care. 2005 Feb;9(1):104-11.

15. Hogan DE, Waeckerle JF, Dire DJ, Lillibridge SR. Emergency department impact of the Oklahoma City terrorist bombing. Annals of Emergency Medicine. 1999 Aug;34(2):160-7.

16. Røislien J, van den Berg PL, Lindner T, Zakariassen E, Uleberg O, Aardal K, et al. Comparing population and incident data for optimal air ambulance base locations in Norway. Scand J Trauma Resusc Emerg Med. 2018 May 24;26(1):42.

17. Wisborg T, Ellensen EN, Svege I, Dehli T. Are severely injured trauma victims in Norway offered advanced pre-hospital care? National, retrospective, observational cohort. Acta Anaesthesiol Scand. 6 ed. 2017 Jun 26;61(7):841-7.

18. Kristiansen T, Søreide K, Ringdal KG, Rehn M, Krüger AJ, Reite A, et al. Trauma systems and early management of severe injuries in Scandinavia: review of the current state. Injury. 2010 May;41(5):444-52.

19. Kristiansen T, Ringdal KG, Skotheimsvik T, Salthammer HK, Gaarder C, Næss PA, et al. Implementation of recommended trauma system criteria in south-eastern Norway: a cross-sectional hospital survey. Scand J Trauma Resusc Emerg Med. 2012;20(1):5.

20. Pedersen MJB, Gjerland A, Rund BR, Ekeberg Ø, Skogstad L. Emergency Preparedness and Role Clarity among Rescue Workers during the Terror Attacks in Norway July 22, 2011. Kumar S, editor. PLoS ONE. 2016 Jun 9;11(6):1-12.

21. Rosenfeld JV, Mitra B, Smit DV, Fitzgerald MC, Butson B, Stephenson M, et al. Preparedness for treating victims of terrorist attacks in Australia: Learning from recent military experience. Emergency Medicine Australasia. 2018 May 9;30(5):722-4.

22. Long AM, Lefebvre CM, Masneri DA, Mowery NT, Chang MC, Johnson JE, et al. The Golden Opportunity: Multidisciplinary Simulation Training Improves Trauma Team Efficiency. Journal of 
Surgical Education. 2019 Aug;76(4):1116-21.

23. Capella J, Smith S, Philp A, Putnam T, Gilbert C, Fry W, et al. Teamwork training improves the clinical care of trauma patients. Journal of Surgical Education. 2010 Nov;67(6):439-43.

24. Lewis AM, Sordo S, Weireter LJ, Price MA, Cancio L, Jonas RB, et al. Mass Casualty Incident Management Preparedness: A Survey of the American College of Surgeons Committee on Trauma. Am Surg. 2016 Dec 1;82(12):1227-31.

25. Ministry of Health and Care Services. Law on health and social preparedness (helseberedskapsloven). LOV-2000-06-23-56 Jul 1, 2001 pp. 1-8.

26. Ministry of Health and Care Services. Regulations on requirements for preparednessplanning and preparednesswork, etc. according to the law on health and social preparedness. FOR-2001-07-23-881 Aug 10, 2001 pp. 1-3.

27. Lennquist S. Education and training in disaster medicine. Scand J Surg. 2005;94(4):300-10.

28. Hojman H, Rattan R, Osgood R, Yao M, Bugaev N. Securing the Emergency Department During Terrorism Incidents: Lessons Learned From the Boston Marathon Bombings. Disaster Med Public Health Prep. Cambridge University Press; 2019 Aug;13(4):791-8.

29. Streiner DL, Norman GR, Cairney J. Health measurement scales: a practical guide to their development and use. 5 ed. Oxford; New York: Oxford University Press; 2015. 